\title{
LAS IDEAS LITERARIAS EN LA PRENSA DE LA ÉPOCA ROMÁNTICA: EL DEBATE «SOBRE LA INFLUENCIA DEL TEATRO EN LAS COSTUMBRES» (A PROPÓSITO DE VARIOS ARTÍCULOS DE MIGUEL AGUSTÍN PRÍNCIPE)*
}

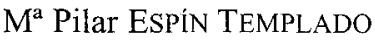

UNED. Madrid.

A ningún estudioso del romanticismo hispánico se le escapa la importancia de la crítica literaria en la prensa como fuente de reconstrucción del pensamiento sobre el teatro de la época. La profusa difusión de ideas literarias, filosóficas y políticas a través de la prensa y revistas más o menos especializadas, influirá en la concepción del hecho teatral y en la creación literaria del «poeta dramático» $y$, es de suponer que, en cierto modo, las condicionará; hay que tener en cuenta que una buena parte de los dramaturgos y escritores románticos fueron asiduos colaboradores en multitud de publicaciones periódicas, y no olvidar que muchos de ellos eran académicos y/o profesores, y por tanto estudiosos, y teóricos de la historia literaria, a la par que creadores. Según estas consideraciones no es arriesgado afirmar la posibilidad de detectar las fuentes que conforman en muchos casos dicho pensamiento.

La influencia literaria ejercida durante esta época por trabajos de crítica periodística fue significativa no sólo en el caso del crítico más emblemático y profesionalizado, Mariano José de Larra, sino en dramaturgos como B. de los Herreros (críticas teatrales en El correo literario y mercantil), Gil de Zárate,

* Este artículo está inserto dentro del Proyecto de Investigación Historia del Teatro Representado en España, BFF2003-07342 (2004-2006) subvencionado por la DGICYT (Ministerio de Educación y Cultura y Ministerio de Ciencia y Tecnología. 
Patricio de la Escosura, Eugenio Hartzenbusch, y otros escritores, ensayistas y críticos como Manuel Milá y Fontanals, Alberto Lista o en los años posrománticos Manuel Cañete; en este contexto podemos situar a M. A. Príncipe (18111863), escritor y periodista prolífico a juzgar por las numerosas publicaciones teatrales en las que colaboró expresando en ellas ideas, críticas y ensayos sobre el teatro de su tiempo, aspecto éste no agotado en la monografía del escritor de Aldea Gimeno y Serrano Dolader (Romero Tobar 1994, pág. 354).

No me interesa aquí revisar la creación de Miguel Agustín Príncipe o su trayectoria biográfica, (ambas ya abordadas por varios estudiosos') durante el periodo romántico/posromántico que le tocó vivir, sino detenerme en sus ideas literarias y sociales sobre el teatro, expresadas con frecuencia en la prensa, y contrastarlas con algunas de sus coetáneos. Trato, por tanto, de sacar a luz el pensamiento acerca de la función social del teatro durante el romanticismo español partiendo de los artículos de prensa del escritor aragonés Miguel Agustín Príncipe (1811-1863), del debate ideológico que se produce con discursos académicos (suyos y de otros escritores,) y de su posible relación con los textos de preceptiva literaria que se manejaban y/o conocían en la época.

La función social de la literatura, en este caso de la literatura dramática, fue un leit-motif de coincidencia entre los temas- tópicos de debate en liceos y ateneos. En la sección de Literatura y Bellas Artes del Ateneo de Madrid, durante los años 1836 a 1839 , «se discutió de los temas que importaban a los escritores y críticos del momento, es decir, sobre los clásicos y los románticos, la validez de las reglas en el teatro moderno, la función social de la literatura, o las novelas históricas y caballerescas. (Ruiz Salvador 1971, págs. 66-73). Príncipe no iba a ser ajeno a esta inquietud:

El hecho literario, en toda su extensión le interesa de una manera absorbente. A lo largo de toda su obra incide, con reiteración, en la crítica y el análisis. Recordemos la importancia de sus sátiras contra las escuelas romántica y neoclásica, su valoración de autores y movimientos en el Prólogo a la colección de Fábulas o sus comentarios formales en el Arte Métrica. Incluso aspectos estrictamente técnicos, pero relacionados con el hecho literario, no escapan a su pluma de abogado, como manifiestan sus artículos sobre el reglamento de teatros y espectáculos en El Entreacto, "Proyectos de reglamento de teatros»

' La semblanza de Príncipe figura en los principales repertorios bibliográficos con más o menos variaciones Ferrer del Rio, Gómez Uriel, Ovilo y Otero, Ossorio y Bernard, Palau. En Historias de la Literatura: Blanco García, Fco.; Cejador y Frauca, J.. También en los más recientes catálogos de dramaturgos o novelistas: Ferreras., Menarini, González Herrán, Penas Varela, Rodríguez Sánchez, y González Subías. Su vida y su obra es estudiada en la citada monografía de Aldea Gimeno-Serrano Dolader 1989. 
(16, enero, 1840); «Reformas teatrales» (9, febrero, 1840). (S. Aldea Gimeno y Serrano Dolader A. 1989, págs. 260-261).

El especial protagonismo del teatro en los años que nos ocupan y su carácter intrínsecamente social dio lugar, como es sabido, a que se debatieran, de una manera reiterativa, las relaciones teatro-sociedad. Se pone ahora más énfasis que en el didactismo de los ilustrados, en la perspectiva del influjo moral que la escena ejercía en los espectadores. En la Real Academia de la Lengua no escasearán los discursos relativos a la función moral de la poesía dramática en la sociedad, como mostraremos más adelante.

Ejemplo de esta especial preocupación por la moralidad del teatro, frecuentemente tratada en la prensa, son los cuatro artículos del Entreacto «Sobre la influencia del teatro en las costumbres», uno de los cuales es rebatido por Pedro Sabater en el Semanario Pintoresco Español, y a su vez contestado por Príncipe en este mismo semanario. Asimismo haremos alusión a otros dos artículos-ensayos aparecidos también en El Entreacto de los años 39 y 40 , y a uno de sus discursos de apertura de curso, el correspondiente al año académico 1838 de la Universidad de Zaragoza, publicado en dos entregas en el mismo semanario, por considerar que estas contribuciones tienen una unidad temática y cronológica ${ }^{2}$.

Miguel Agustín Príncipe desarrolla su tesis de la influencia del teatro en la moral del espectador, y por tanto de la responsabilidad del poeta dramático, y en última instancia del Estado, de preocuparse de la moralidad de la escena. En sus cuatro primeros artículos citados parte de cuatro opiniones, a su juicio equivocadas pero muy comunes, que intenta rebatir. Expone en primer lugar la idea controvertida para rebatirla a su vez esgrimiendo sus argumentos, $y$ las consecuencias que se deducen de los mismos.

Un análisis pormenorizado de ellos nos revela las ideas candentes que preocupaban a los españoles del siglo XIX acerca de la esencia del hecho teatral y la polémica que suscitaba respecto a sus relaciones con la sociedad. Intentaremos desbrozarlas a luz de la mentalidad y conocimientos propios de la época.

La cuestión que plantea M. A. Príncipe en su primer artículo, de los cuatro que componen la serie Sobre la influencia del teatro en las costumbres (El Entreacto, 8, agosto,1839), es si el teatro es mera institución de recreo público

2 Me ciño, pues, en esta exposición a las siguientes: «Sobre la influencia del teatro en las costumbres»: Cuatro artículos en El Entreacto ( 8 y 22 de agosto, 1 y 15 de septiembre de 1839), más la contestación de Pedro Sabater a su tercera entrega en el Semanario Pintoresco Español el 8 de septiembre, y la respuesta, de M. A. Príncipe en este mismo hebdomadario, el 21 del mismo septiembre de 1839; las dos entregas tituladas «iEs la literatura la expresión o relato de la época en que se escribe? ¿Debe serlo? en El Entreacto del 10 y 21 de noviembre de 1839 , y su discurso de apertura de 1838 de la Universidad de Zaragoza, publicado en El Entreacto del 5 y del 8 de marzo de 1840: Ni sociedad sin literatura, ni literatura sin sociedad. 
$o$, por el contrario, una institución influyente en la moral de la sociedad en la que haya que reconocer «un elemento efectivo de moralidad o desmoralización, según se dirija». Príncipe, en contra de la idea expresada por Larra, «...El teatro rara vez corrige, así como también rara vez pervierte...», que ni el mismo Fígaro comparte, en acertada opinión de Príncipe, si se examinan sus invectivas contra el Antony.) concluye que «la influencia que ejerce en las costumbres no puede menos de considerarse como una verdad reconocida».

Su argumentación, bastante endeble y subjetiva, se basa en que los modelos de virtud o vicio ejercen influencia especialmente en los espectadores «jóvenes y en las mujeres cuyas almas son demasiado sensibles al imperio de las impresiones». El hombre como animal «esencialmente imitador» es susceptible de recibir «la influencia de los grandes cuadros que el teatro le presenta como dignos de ser imitados» y es todavía más sumiso al influjo de los malos ejemplos porque desgraciadamente es «de suyo inclinado al mal» «y de aquí la mayor facilidad en hacerle caer, que en levantarle una vez caído».

En el artículo II de esta serie (El Entreacto 22, agosto,1839) Príncipe plantea la debatida cuestión de si es el teatro retrato de las costumbres de la sociedad o reflejo de las mismas: «en contra de los que se preguntan que si el teatro es copia exacta de las costumbres del mismo público que lo frecuenta: ¿cómo pues las ha de introducir en un pueblo de quien él mismo las recibe?».

M. A. Príncipe insiste en diferenciar los términos costumbres y moral. El término moral es confundido por la sociedad con la ausencia de la misma: «costumbres corrompidas de un pueblo, libertinaje, relajación de vínculos sociales, los vicios en suma de una sociedad», frente a lo que en su opinión se debe entender por costumbres que define como «el conjunto de usos, ritos ceremonias, trajes y maneras de los individuos de un pueblo, su modo particular de existir a diferencia de los demás, o por decirlo de alguna manera el carácter «histórico» de una sociedad cualquiera en época y circunstancias determinadas».

Vemos aquí el carácter historicista del pensamiento de Príncipe al defender la obra de arte como propia de un pueblo, y consecuentemente derivada del carácter y de la moral de una sociedad concreta, cuando afirma que «el drama que se refiera a esa sociedad y a esa época debe ser su retrato y su copia presentando los rasgos característicos que constituyen su fisonomía particular so pena de ofrecer a los espectadores una idealidad quimérica y sin analogía de ninguna especie con la verdad histórica».

En este sentido, según Príncipe, sobre dichas costumbres, debe el poeta montar su drama para no cometer anacronismos ni confundir «los usos y el 
espíritu dominante de un pueblo con los usos, maneras, y costumbres de otro» ${ }^{3}$ «...pero no por eso los dramas deben acomodarse a la moral de un pueblo relajado, adulando sus pasiones, o haciendo el apoteosis de sus vicios». En consecuencia: el drama debe ser retrato y copia de la fisonomía particular de esa sociedad de acuerdo con la verdad histórica, para evitar anacronismos y no confundir sus usos y costumbres con los de otro pueblo. Las costumbres son norma del teatro en cuanto el pueblo-público le presta asunto o materia, el teatro es norma de esas mismas costumbres en cuanto aplaude o reprueba las conductas respetuosas o no con la moral.

El artículo III, (1, septiembre,1839) rebate la idea de que sólo adulando las pasiones del espectador, pueden los poetas dramáticos aspirar a que se les escuche con gusto. Según Príncipe esta veleidad y exigencias que se atribuyen al público, son relativas tan sólo «al gusto, al sabor literario de las piezas dramáticas, y nada más», pero la moralidad está fuera de las exigencias que se atribuyen al público. Este es el punto que será rebatido por Pedro Sabater en Semanario Pintoresco Español (8 de septiembre de 1839) quien afirma categóricamente (no sin antes exponer multitud de ejemplos de la literatura clásica) que «las costumbres influyen en la literatura más que la literatura en las costumbres» ya que «el pueblo quiere que se le hable de sus costumbres, de sus pasiones y de sus deseos..» algo a lo que no se pueden sustraer los poetas «no por el sólo deseo de halagar al pueblo, sino porque no han podido resistir al torrente de su época», siendo sus inspiraciones irremediablemente influidas por las costumbres dominantes; por esa razón se explican, según Sabater «esos argumentos impúdicos, esos suicidios centuplicados, y esos caracteres inmorales y grotescos de nuestros dramas actuales...(los cuales) significan la anarquía que domina en las ideas y representan el desquicio en que se halla la sociedad»?.

El 21 del mismo mes de septiembre, M. A. Príncipe contestaba «al erudito y apreciable discurso de D. Pedro Sabater» en el mismo Semanario Pintoresco Español rogándole la lectura del anterior artículo suyo, en el que distingue lo que entiende por «ceder al gusto particular de los pueblos y a sus inclinaciones y afectos en todo lo que no se oponga a los eternos principios de justicia y de moral». El debate se zanja con una nota del Semanario ${ }^{4}$.

${ }^{3}$ Nos remite al Discurso de Durán «el teatro debe ser en cada país la expresión poética e ideal de sus necesidades morales, y de los goces adecuados a la manera de existir, sentir y juzgar de sus habitantes; circunstancias todas que influyen poderosamente en el modo de la inspiración fatídica y que nunca serán el resultado del arte ni del análisis metafísico o erudito de obras extranjeras y opuestas al carácter de cada puebjo» (R. Navas-Ruiz 1971, págs. 62-63).

${ }^{4}$ Dice así la NOTA: «No permitiendo la particular forma de nuestro Semanario en dar en él lugar a polémicas literarias, por muy útiles que nos parezcan, rogamos a los apreciables escritores 
En este mismo artículo tercero define el concepto de público como conjunto de espectadores que se erigen en una masa común de virtud y moralidad en la que éstos «no son ya los individuos particulares que representan una pequeña parte de la sociedad particular a que pertenecen sino los representantes de la humanidad entera» que distinguen muy bien al malvado o al virtuoso que en la escena actúan como tales.

Finalmente, en el artículo IV, rebate la tesis de que la influencia del teatro sea nula "porque se presentan dramas que alternativamente proclaman principios contradictorios según la índole de las diversas piezas que en él se representan.» Príncipe alega que esto lo único que prueba es «la mala dirección que se da a los teatros, no la nulidad de su influencia»r. Ni es nula, ni es escasa, porque no son tan pocos los que asisten al teatro ya que los espectadores, aunque sean una minoría, comunican su experiencia teatral a la sociedad que se relaciona con ellos. También, sin asistir al teatro, la lectura de los dramas ejerce su influencia de la misma manera que las novelas.

En conclusión, la escena, para Príncipe es una institución eminentemente política, como la cátedra o la prensa:

adúnense los tres para el grande objeto de ilustrar y hacer felices a los pueblos... sea objeto de una ley que pueda contener sus abusos y hacerle tan útil como puede serlo y entonces será el teatro verdadera escuela de educación pública...No nos cansemos de repetirlo: en naciones como la nuestra, los elementos de la ilustración y de la moralidad son cuatro: el púlpito, la prensa, los establecimientos científicos y el teatro.

Como se puede observar, en estos artículos se translucen una serie de conceptos estéticos y de ideas literarias sometidas a debate público con mucha frecuencia en la época. Fundamentalmente incide Príncipe en la función de la obra literaria, que concretándose en el drama, se ciñe al objeto moral de la representación. La cuestión moralizante del teatro destaca en estos años culminantes del romanticismo español (desde 1834 hasta la mitad de siglo), constituyendo una de las cuestiones polémicas más aireadas en la prensa. La finalidad moral del teatro, que para los preceptistas era considerado un deber, para los periodistas de estos años pasa a ser consustancial con la realidad histórica y circunstancial, esgrimiendo la comparación entre el Teatro y la Historia como «maestra de la vida» (Romero Tobar 1974, pág. 20). En Príncipe se contemplan ambas consideraciones. M. A. Príncipe no niega el carácter lúdico del teatro, pero siempre que no vaya en contra de la moral: «Todo lo más que puede concederse al poeta dramático es que escriba para «divertir», pero con la condición indispensable de no verificarlo a expensas

que han promovido esta, que la den por terminada, supuesto que parecen estar acordes en cuanto al fondo de la cuestión»y. 
de la moral. (Art. II)....si algo exige (el público) de los poetas dramáticos, es que se manifiesten en sus obras virtuosos y hombres de bien»(Art.III).

Varias ideas de las expuestas en estos artículos de Príncipe recogen los principios de Retórica y Poética que se impartían por esos años en la Universidad como los conceptos del gusto, de lo bello, de la realidad, y de la copia o retrato artístico de la realidad de acorde con la verdad histórica y con la verdad moral.

Para Príncipe el buen gusto, es aquel que, de acuerdo con una recta moralidad, fortalece los vínculos sociales, y será consolador para la humanidad, y por tanto bello. ( «Ni sociedad sin literatura, ni....»). El gusto de los pueblos está en proporción a su grado de civilización y cultura: «El gusto de los pueblos varía a proporción de los mayores o menores progresos de su civilización y cultura»(Art. III) y los poetas se ven precisados a acomodarse a él siempre que se respeten los principios de gusto y belleza universal:» El poeta se ve precisado a acomodarse al gusto peculiar de su siglo: con tal que respete los principios fundamentales del gusto y de la belleza universal» (Art. III).

En cuanto al teatro como retrato y escuela de costumbres: «¿Por qué ha de ser imposible retratar al pueblo que asiste al teatro, y al paso que se le retrata confirmarle en sus buenos principios, o presentarle a la vista las consecuencias de sus errores, dándole una lección provechosa? (subrayado mío). Si bien la insistencia en el docere horaciano no supone novedad en la preceptiva del S. XIX, sin embargo, sí es de destacar que, a medida que avanza el siglo, se relaciona con el impulso educador $y$, con la reforma de la enseñanza que tiene lugar a partir de los años 40. (M. J. Rodríguez Sanchez de León 1990, Nota 43, pág. 93).

El retrato de costumbres debe ser acorde con la verdad histórica: «Representación de una sociedad cualquiera en época y circunstancias determinadas en analogía con la verdad histórica» (Art.II). Sin embargo M. A. Príncipe matiza esta afirmación cuando afirma «Yo creo que la literatura participa siempre poco o mucho del carácter de la época en que se escribe, pero niego que para merecer el nombre de tal se haya de ver precisada a ser constantemente el retrato, la copia, el fac simile, digámoslo así, del siglo a que pertenece...»(en «¿Es la literatura la expresión o retrato...?»).

Defiende un concepto de público como «ente moral», cuyos componentes, los espectadores son los representantes de los principios inmutables de la moral humana:

Un sentimiento de moralidad profundamente arraigado en el corazón humano, hace que los espectadores, cualesquiera que sean sus principios literarios y su 
conducta privada, anhelen ver en la escena erguida y triunfante la inocencia, respetado el pudor, anatematizados los crímenes (Art.III) $)^{5}$.

Revisando la andadura biográfica de Príncipe vemos la coincidencia de los años en que publica estos artículos 1839 y 1840 con el ejercicio de su docencia universitaria (1836-1839), en la que sabemos que reemplazó el libro de texto de Retórica de Hugo Blair, que había impartido su predecesor De Quinto en el curso 1836-1837, por los de Iriarte y Francisco Sánchez Barbero Fábulas literarias y Principios de Retórica y Poética respectivamente, (autores que vuelven a repetirse en el plan del curso siguiente 38-39, como así consta en el Plan general de estudios de la Universidad Literaria de Zaragoza de 1837-38 (Buesa Oliver 1983, págs. 39-40).

Es decir, Príncipe, igual que su antecesor en la cátedra De Quinto, al elegir los textos mencionados, había seguido «la concepción estética de los liberales españoles de comienzos de siglo frente a los que secundaron los Principios filosóficos de la literatura del abate Batteux, en su traducción de Agustín García de Arrieta, alineados en los defensores de los valores nacionales a ultranza.» (Rodríguez Sánchez de León 1990, pág. 80), aunque parece ser que esta obra también influye en su tarea de crítico musical (Romero Tobar 1986, pág.16) ${ }^{6}$.

En Príncipe se observa cierta tolerancia en el alejamiento de la preceptiva tradicional aristotélica, según la cual el poeta podía infringir las leyes del arte siempre que la moral dramática quedara salvaguardada; así lo manifiesta claramente en su artículo III:

Importa poco que sus dramas tengan tres jornadas, o que pasen de cinco; que observe estrictamente las unidades de lugar y tiempo o se tome el racional ensanche que le permita el gusto particular del público; que la acción proceda con pausa, o con rapidez y energía... pero la moralidad está fuera del círculo de las exigencias que se atribuyen al público.

Su teoría se aleja por tanto de la doctrina de José Gómez Hermosilla El arte de hablar en prosa y verso de 1826 y de la Poética española de Martínez de la

${ }^{5}$ Igual noción de público teatral encontramos en la obra de Lombía: «...en el teatro es donde el egoísmo pierde todo su imperio...el individuo puede preferir los vicios, pero el público sólo ensalza las virtudes....por grosero que sea el hombre individualmente, no sufre en la escena nada que hiera las buenas costumbres...los mismos (espectadores) en el teatro representan la fuerza moral unitaria a la cual todo debe someterse» (1845, pág. 145).

- Romero Tobar (1986 pag. 16) opina respecto a la formación literaria de Príncipe: «parece bastante seguro que sus bases de lectura están en los modelos clásicos latinos y españoles que se explicaban en los cursos de Retórica y Poética y en heterogéneos autores franceses del siglo XVIII»). Y en sus opiniones, Príncipe deja ver las «autoridades teóricas a las que acude tanto cuando fue docente de Retórica en la Universidad de Zaragoza-Los Principios de Sánchez Barbero- como en su etapa de crítico musical y literario-Los principios Filosóficos de la Literatura del abate Batteux»». 
Rosa de 1827, que postulaban el deseo de que la norma de los escritores de la antigüedad imperara en la escena, siendo esencial para el cumplimiento de la función moral del teatro la sujeción estricta a las normas aristotélicas (M. J. Rodríguez Sánchez de León 1990, pág. 90).

Príncipe se muestra más flexible, siendo más afín a la línea que don Alberto Lista expone en sus Lecciones de Literatura Española impartidas tres años antes en el Ateneo de Madrid. El poeta podía transgredir alguna norma en el uso de las leyes específicas del arte antiguo pero era tajante respecto de las que atendían a la moralidad de las composiciones: «Lo que importa es no convertir en dogma lo que solo fue propio de la literatura griega y romana» (artíc.III). Distingue entre principios inmutables en literatura y otros perfectamente susceptibles de cambio «...en la literatura hay principios inmutables, y los hay transitorios o de pura «localidad»: el público puede manifestarse impunemente veleidoso respecto a estos, y el poeta ceder a sus exigencias respetando aquellos (art.III), , ideas que coinciden exactamente con las palabras de A. Gil de Zárate: «si hay reglas que... han podido modificarse, existen otras que están fundadas en los principios eternos de la razón y, por lo tanto nunca se infringirán impunemente» (A. Gil de Zárate 1842, pág. 13).

A mediados de siglo se evoluciona hacia un realismo limitado por los principios de la verdad y la belleza conformes a una moral establecida. Se atiende a un criterio de lo estético comprometido con el valor de la verdad atribuido a la civilización cristiana como en A. Lista o Gil de Zárate. En este sentido, «preocupaba más que el drama fuera la escenificación moral de las costumbres que una muestra fiel de los preceptos aristotélicos» (M. J. Rodríguez Sánchez de León 1990, págs. 94-95). Miguel Agustín Príncipe se anticipa a los postulados de esta corriente en los últimos años de la década de los treinta.

Estos mismos temas continuarán apareciendo y debatiéndose veinte años después en discursos académicos, como en el de Manuel Tamayo y Baus de $1859^{7}$, en el que las ideas de belleza y verdad moral serán los límites que el arte se deba imponer para copiar la realidad:

el arte no copia maquinalmente lo real «porque en ese caso dejaría de ser bella y pecaría de falsa...cuando pinte con minuciosa exactitud,.... el arte debe escoger los elementos de la realidad dignos de figurar en él.....amalgamando lo bello con lo verdadero.».... «la verdad será siempre a la vez origen de belleza artística y de belleza moral» «Es dado al arte ejercer saludable y poderoso influjo, despertando afectos nobles y generosos, puras y elevadas aspiraciones (M. Tamayo y Baus 1859 , pág. 266).

${ }^{7}$ «De la verdad considerada como fuente de belleza en la Literatura dramática», 12 de junio de 1859 . 
También el discurso de T. Rodríguez Rubí, de $1860^{\circ}$ reincide en la idea de un teatro como institución no únicamente lúdica, a la vez que escuela y reflejo de costumbres de importantes repercusiones morales y económicas: «institución secular», cuya «acogida con delirio en todas las épocas» patentiza que «el teatro lleva en sí el germen de algo más que el recreo y el pasatiempo; que «su objeto no es simplemente el de distraer los espíritus perezosos o preocupados» ( $\mathrm{T}$. Rodríguez Rubí 1860, pág. 422), «bien entendido, es, y forzosamente debe serlo, escuela, por las lecciones que se dan en él, de buena doctrina, de avisos elocuentes, de plausibles ejemplos de costumbres» (Ibidem, pág. 430) «y reflejo de éstas por el retrato que de ellas hace; debe cumplir un objeto común: el de enseñar y retratar. En todas (las obras dramáticas citadas como ejemplo) hay lección... en todas hay reflejo porque hay dibujo de costumbres (Ibidem, págs. 427-28, cursivas mías).

Y llegando hasta el mismo año de la Revolución del 68, el discurso del académico Leopoldo Augusto de Cueto, trata del «Sentido moral del teatro», y es prolijo en afirmaciones del mismo corte en cuanto a la influencia del teatro:

El teatro es indudablemente un medio trascendental de propagar ideas y de despertar y acalorar sentimientos. Su influencia puede ser sana o perniciosa, a medida del espiritu que lo anime y alimente (L.A. de Cueto 1868, pág. X)

La diferencia ahora es que los dramas, tan denostados moralmente, de $\mathrm{V}$. Hugo y A. Dumas durante los años del Romanticismo, ahora son ya son valorados desde otra perspectiva y encumbrados bajo la disculpa moral de la creación artística de un mundo imaginario, no real:

el mundo moral que trasladaban al teatro no era, por cierto, el mundo real, con las pasiones, los lances y los sentimientos comunes de la vida humana. Era el mundo de la imaginación, que a todo trance buscaba lo grande y lo extraordinario, aun a costa de la verdad... esos creadores de un mundo moral imaginario, no pocas veces monstruoso, jamás envilecieron el arte, jamás hicieron descender los sentimientos del alma humana al ínfimo nivel a que los ha traído la escuela cínica (se refiere a la realista) de la era presente (L.A. de Cueto 1868, págs. 40-41).

Compárese este juicio con las acaloradas invectivas de que fueron objeto esos mismos escritores franceses dos décadas antes, entre otros muchos por Ventura de la Vega en su discurso de ingreso a la Academia:

....así fue erigiéndose en máxima el peligroso argumento de que para hacer odioso el vicio es preciso retratarle, y de aquí resultó que se presentaban al público cuadros de tal suerte combinados, que el vicioso aparecía disculpado y

\footnotetext{
${ }^{8}$ «Excelencia, importancia y estado presente del teatro», 17, junio, 1860
} 
hasta amable, porque sus vicios y sus crímenes se achacaban a la mala organización de la sociedad.... y los empresarios de aquellos espectáculos, más mercantiles que literarios, trataron de atraerlo a costa del arte, y lo consiguieron efectivamente, prostituyendo la escena a los monstruosos dramas de V. Hugo, A. Dumas... Rompió la marcha Lucrecia Borgia... llovieron sobre el teatro dramas de este jaez Teresa, Antony, Angelo...

Una vez más lo nuevo es desechado como escándalo que atenta a la moral: antaño lo romántico, que ahora es sublimado por una aureola artística, ahora lo realista es denostado como atentado contra la moral, la belleza y la verdad.

La divulgación periodística y los discursos en los foros académicos (Real Academia) y artísticos (Liceo, Ateneo) sobre las ideas literarias de muchos escritores influirán en la concepción de la creación artística y en el pensamiento de la época; también es evidente la relación de dichas ideas con una tradición de estudios y conocimientos de la preceptiva clásica ya adquiridos, pero no es menos obvio que aquellas y estos van evolucionando en su adaptación a la nueva mentalidad de los tiempos. 


\section{BIBLIOGRAFÍA}

Aldea Gimeno, S.; Serrano Dolader, A.,1989. Príncipe, Miguel Agustín. Escritor y periodista (1811-1863), Zaragoza, Institución Fernando el Católico.

BLAIR, H., 1817 ( $3^{\mathrm{a}}$ ed.). Lecciones sobre la Retórica y las Bellas Letras por Hugo B. Las tradujo del inglés Don José Munarriz, Madrid, Ibarra, Impresor de Cámara de S.M., Tomo IV.

BLAIR, H. y F. SÁNCHEZ BARBERO,1854. Curso elemental de Retórica y Poética. Retórica de Hugo Blair. Poética de Sánchez. Textos aprobados por el Real Consejo de Instrucción Pública, ordenados, corregidos y adicionados... por D. Alfredo Adolfo Camus, Madrid, Librería de León Pablo Villaverde.

Buesa Olver, T., 1983. Años universitarios de M.A. Principe, Zaragoza, Institución Fernando El Católico.

- [1837] 1983. «Miguel Agustín Príncipe, primer paraninfo zaragozano en lengua española», Serta Philologica F.Lázaro Carreter. Estudios de Literatura y critica textual, Madrid, Cátedra, II, págs.113-125.

Cebrián, J., 1990. "Significación y alcance de la Poética de Martínez de la Rosa», Revista de Literatura, Madrid, LII, 103, págs.129-150.

CEJADOR Y FRAUCA, J., 1972. $H^{a}$ de la Lengua y Literatura Castellana, Madrid, Gredos, ed. facsímil de M. Tipografía de la Revista de Archivos, Bibliog. Y Museos, 1917, Tomo IV .

CUETO, L.A. de, 1868. «Sentido moral del teatro»Discurso escrito por el Excmo.

Sr. D. L.A. de Cueto, individuo de número de la R.A.E. y leido en la Junta

Pública Inaugural de 1868, Madrid, Imprenta de M. Rivadeneira.

FERRERAS, J.I., 1979. Catálogo de novelas y novelistas españoles del Siglo XIX, Madrid, Cátedra.

GIL DE ZÁRATE, 1853 ( $6^{\mathrm{a}}$ ed. corrg. y aum.). Principios generales de Retórica

y Poética: Primera parte del Manual de literatura, Madrid, Imprenta de Gaspar y Roig.

GonZÁlez SubíAS, J.L., 2005. Catálogo de estudios sobre el teatro romántico español y sus autores. Fuentes bibliográficas, Madrid, Fundación Universitaria Española.

GonzÁlez Herrán, J.M. y E. Penas VAREla, 1992. Cronología de la Literatura Española. III, S.S. XVIII, XIX, Madrid, Cátedra.

LoMBíA, J., 1845 (en la portada por error 1545). El teatro. Origen, indole e importancia de esta institución en las sociedades cultas, Madrid, Imprenta de Sanchiz.

Menarini, P. y P. GARELli 1982. El Teatro Romántico español, Bologna, Atesa Editrice. 
Navas-Ruiz, R., 1971. El Romanticismo Español. Documentos, Salamanca, Anaya.

PÉreZ SÁnCHEZ, A., 2005. El Liceo Artístico y Literario de Madrid (1837-1851), Madrid, Fundación Universitaria Española.

RoDRíGuez RUBí, T., 1860. «Sobre la excelencia, importancia y estado presente del teatro». Contestación por D. Antonio Ferrer del Río», Discursos leidos en las recepciones públicas que ha celebrado desde 1847 la Real Academia Española, Madrid, Imprenta Nacional, $1^{\mathbf{a}}$ serie, tomo segundo.

Rodríguez SÁnchez, T., 1994. Catálogo de dramaturgos españoles del Siglo $X I X$. Madrid, Fundación Universitaria Española.

RODRIGUEZ SÁNCHEZ DE LEÓN, M. J., 1990. «El teatro español del siglo de Oro y la preceptiva poética del siglo XIX», Clásicos después de los clásicos. Cuadernos de Teatro Clásico, n ${ }^{\circ}$, Madrid, C.N.T.C., págs. 77-98.

ROMERo TOBAR, L., 1974. La teoría dramática española: 1800-1870. Madrid, Facultad de Filosofía y Letras, extracto de Tesis Doctoral.

- 1986. «Plano para leer a M.A. Príncipe», Andalán, n 463. Zaragoza, nov., pág. 16.

- 1994. Panorama crítico del romanticismo español, Madrid, Editorial Castalia.

Ruiz Salvador, Antonio, 1971. El Ateneo Cientifico Literario y Artístico de Madrid (1835-1885), London, Tamesis Books.

TAMAYO Y BAUS, M., 1859. «De la verdad considerada como fuente de belleza en la literatura dramática». Discursos leidos ante la Real Academia Española en la recepción pública de Don Manuel Tamayo y Baus, el 12 de junio de 1859. Contestación de D. Aureliano Fernández-Guerra y Orbe, Madrid, Imprenta de M. Rivadeneira.

VEGA,V. de la, 1870. «Discurso que leyó D. Ventura de la Vega al tomar asiento en la Academia» (Madrid, 3, febr., 1842), Memorias de la Academia Española, Madrid, Imprenta Rivadeneira, Año I, Tomo II. 